\title{
Laboratório de Turismo \& Hospitalidade: aprimorando competências em ensino, pesquisa e extensão
}

\author{
Ana Lúcia Olegário Saraiva a; Bianca Pugen b; Vanessa de Souza Chaves c
}

\begin{abstract}
RESUMO
O Laboratório de Turismo e Hospitalidade é um espaço de aprendizagem voltado para docentes e discentes dos cursos do Eixo Tecnológico de Turismo, Hospitalidade e Lazer do Instituto Federal de Educação, Ciência e Tecnologia do Rio Grande do Sul (IFRS) - Campus Osório. Tem como finalidade ser um núcleo de referência educacional para atendimento às demandas da instituição e da comunidade externa. A proposta é desenvolver atividades práticas voltadas ao ensino, pesquisa e extensão, nas formas de organização e/ou apoio para que os alunos possam desenvolver competências, conhecimentos, habilidades e atitudes, contemplando uma formação teórico-prática que amplie as aptidões para atuação profissional. $O$ artigo se propõe a relatar a experiência da instalação do Laboratório de Turismo e Hospitalidade, demonstrando a importância do planejamento das atividades pedagógicas, sem dissociação entre teoria e prática na Educação Profissional. Como primeiros resultados da sua instalação, menciona-se a realização de cursos de extensão demandados tanto pela comunidade interna como pela comunidade externa e o desenvolvimento de um projeto de pesquisa, corroborando para o desenvolvimento de conhecimentos, de saberes e de competências profissionais e pessoais requeridas pela natureza do trabalho em Turismo e Hospitalidade.
\end{abstract}

\section{Palavras-chave}

Turismo

Laboratório

Competência

Aprendizagem 


\section{INTRODUÇÃo}

O mundo do trabalho tem apresentado diversas exigências para que os profissionais possam atuar em Turismo e Hospitalidade, principalmente no tocante ao desenvolvimento de competências inovadoras destes profissionais. O aprimoramento destas competências tem sido um desafio para as Instituições de Ensino (IE).

Estas instituições devem estar atentas às mudanças que envolvem a legislação específica da área, as demandas de competitividade atuais e a mudança no perfil profissional. Além disso, necessitam atentar para a elaboração dos planos de cursos e para as demandas de origem teórico-práticas que devem contemplar uma formação que desenvolva de forma integral o sujeito para atuação profissional.

Para tal desenvolvimento, que contemple competências, habilidades e atitudes, foi estruturado um espaço de aprendizagem denominado "Laboratório de Turismo e Hospitalidade" como projeto de ensino vinculado ao Eixo Tecnológico Turismo, Hospitalidade e Lazer, no IFRS - Campus Osório.

Foi planejado como um ambiente voltado para docentes e discentes dos cursos integrados ao referido eixo e tem como principal objetivo ser um núcleo de referência educacional em Turismo, Hospitalidade e Lazer na região do Litoral Norte Gaúcho.

O presente artigo tem como objetivo relatar a experiência da instalação do Laboratório de Turismo e Hospitalidade, demonstrando a importância do planejamento das atividades pedagógicas, sem dissociação entre teoria e prática na Educação Profissional.

O artigo está estruturado em três partes. Na primeira, são apresentados os referenciais teóricos que subsidiaram a estruturação da proposta do laboratório versando sobre competências, educação profissional e a construção do projeto pedagógico do curso técnico em eventos.

Na segunda parte é apresentado o processo de instalação do Laboratório de Turismo e Hospitalidade, seguidos dos resultados alcançados e da aplicabilidade decorrentes de suas ações no ano de 2018.

Por fim, a terceira parte apresenta as considerações finais, abordando os fatores limitadores e facilitadores do projeto, demonstrando, também, a importância do planejamento das atividades pedagógicas.

\section{Referencial Teórico}

\section{As competências para o mundo do trabalho}

Há mais de uma década a educação no Turismo, conforme já relatava Trigo (2008), atravessa um momento em que se faz necessário, de forma urgente, a rever conceitos, métodos e procedimentos para incrementar a qualidade da atuação dos profissionais do Turismo no mundo do trabalho.

Buratto, Tomelin e Hostins (2013. p. 159) afirmam que, dentre os desafios para as Instituições de Ensino (IE), está "[...] prover estruturas curriculares e métodos de aprendizagem que possam responder as rápidas transformações da sociedade".

O mercado de trabalho atual exige profissionais com competências inovadoras, que contemplem o perfil para atuar em Turismo e Hospitalidade, cujo aprimoramento é uma instigação para as IEs.

Estas, precisam estar atentas aos processos de mudanças que envolvem a legislação específica da área, as demandas do mercado e os perfis profissionais atuais, para que possam elaborar planos de cursos técnicos que atendam demandas de origem teórico-práticas que, por sua vez, contemplem a formação profissional que corresponda às demandas atuais.

Tanto a Educação como o mundo contemporâneo estão passando por transformações estruturais significativas, decorrentes do avanço da ciência, o que universalizou as formas de vida do homem moderno, proporcionando-Ihe novas situações de experiências em âmbito local e universal (Gesser, 2013).

Cortelazzo et al. (2018) afirma que se faz necessária uma mudança na forma de educar e que, hoje, o conhecimento deve incluir o raciocínio crítico, a capacidade de se expressar em múltiplos meios e de diferentes formas com capacidade de resolver problemas, utilizando-se de vários fatos e informações, transformando-os para resolver outros problemas.

O mercado num mundo globalizado além de exigir competências técnicas, requer "[...] pessoas com experiências técnicas e comportamentos que geram um saber, e o saber conhecer; a ética é a dimensão que não pode ser dissociada do bloco de 
competências na formação do cidadão que se prepara para o mercado de trabalho [...]" (Brasil, 2016, p. 131).

Segundo Perrenoud (1999) competência é a faculdade de mobilizar um conjunto de recursos cognitivos (saberes, capacidades, informações etc.), para solucionar com pertinência e eficácia uma série de situações.

É um conjunto de conhecimentos (saberes), habilidades (saber - fazer) e atitudes (saber - ser); manifestam-se por comportamentos observáveis; trazem implícitos os conhecimentos tecnológicos e as atitudes e valores inerentes à realização do trabalho.

Para Fleury e Fleury (2001, p. 188) a noção de competência está associada a verbos como: "[...] saber agir, mobilizar recursos, integrar saberes múltiplos e complexos, saber aprender, saber, engajar-se, assumir responsabilidades, ter visão estratégica".

Ciavatta e Ramos (2012, p. 22) afirmam que os componentes da competência podem ser descritos como o "saber", o "saber fazer", o "saber ser" e o "saber conviver". A competência só existiria quando esses "saberes" fossem mobilizados e articulados para a resolução de problemas no campo de atuação profissional.

Assim, "[...] o uso do termo na sua declinação plural e na sua fragmentação em categorias que remetem diretamente às aptidões supracitadas: os 'saberes', o 'saber-fazer' e o 'saber-ser'" (Sulzer, 2004. p. 94).

Portanto, as IE devem elaborar seus planos de curso técnico focando o desenvolvimento integral do aluno, orientados por competências que corroborem na formação de um perfil integral do aluno.

\section{A educação profissional e o desenvolvimento de competências}

Conforme apontam as orientações do Ministério da Educação (MEC) para subsidiar o desenvolvimento do modelo de Educação Profissional preconizado pela legislação educacional, o desenvolvimento de competências supõe a adoção de metodologias centradas no sujeito que aprende, ancorando-se no planejamento sistemático das atividades pedagógicas, em termos de atividades, desafios ou projetos para o exercício das competências pretendidas.
Desta forma, as atividades práticas devem ser contempladas no planejamento das atividades pedagógicas, pois não há dissociação entre teoria e prática para a Educação Profissional. O ensino deve contextualizar competências, visando significativamente à ação profissional. A prática é considerada como metodologia de ensino que contextualiza e põe em ação o aprendizado (Resolução CEB n. 4, 1999).

A Lei de Diretrizes e Bases da Educação Nacional (Lei n. 9.394, 1996) preconiza no seu artigo 39 - "A educação profissional, integrada às diferentes formas de educação, ao trabalho, à ciência e à tecnologia, conduz ao permanente desenvolvimento de aptidões para a vida produtiva".

A Educação Profissional redefine as novas exigências do sistema produtivo, referenciadas pelo conhecimento científico e tecnológico dos agentes da produção - os gerentes e os trabalhadores (Souza \& Silva, 1997).

Os cursos de Educação Profissional Técnica de Nível Médio têm por finalidade proporcionar ao estudante conhecimentos, saberes e competências profissionais necessários ao exercício profissional e da cidadania, com base nos fundamentos científicos-tecnológicos, sócio históricos e culturais (Resolução CNE/CEB n. 6, 2012).

As Diretrizes para a Educação Profissional e Técnica de Nível Médio apresentam o trabalho como princípio educativo, integrado à ciência, à tecnologia e à cultura como base da proposta políticopedagógica e do desenvolvimento curricular.

O currículo de quaisquer dos cursos da modalidade de Educação Profissional Tecnológica, em todas suas formas de oferta e de organização deve ser construído a partir destes dois eixos norteadores essenciais: o trabalho como princípio educativo e a pesquisa como princípio pedagógico.

Ainda, deve apresentar a identidade dos perfis profissionais de conclusão de curso, que contemplem conhecimentos, competências e saberes profissionais requeridos pela natureza do trabalho, pelo desenvolvimento tecnológico e pelas demandas sociais, econômicas e ambientais; bem como a articulação com o desenvolvimento socioeconômicoambiental dos territórios onde os cursos ocorrem, observando os arranjos sócio produtivos e suas demandas locais, reconhecendo assim, as diversas formas de produção, dos processos de trabalho e 
das culturas a eles subjacentes, as quais estabelecem novos paradigmas.

Neste contexto do mundo do trabalho, o Conselho Nacional de Educação e da Câmara de Educação Básica definem em suas normativas, que as expressões competência e autonomia intelectual, utilizadas de forma associada, devem ser entendidas como a capacidade de identificar problemas e desafios, visualizando possíveis soluções e tomando as decisões devidas, no tempo adequado, com base nos conhecimentos científicos e tecnológicos e alicerçado em sua prática profissional e nos valores da cultura do trabalho (Parecer CNB/CEB n. 11, 2008).

A indissociabilidade entre educação e prática social, teoria e prática no processo de ensino-aprendizagem, garantem a interdisciplinaridade no currículo e na prática pedagógica. Visam à superação da fragmentação de conhecimentos e de segmentação da organização curricular.

A contextualização, flexibilidade e interdisciplinaridade na utilização de estratégias educacionais vão ao encontro da compreensão de significados e da integração entre a teoria e a vivência da prática profissional. Além disso, envolvem as múltiplas dimensões do Eixo Tecnológico do curso e das ciências e tecnologias a ele vinculadas.

As atividades compreendidas no Eixo de Turismo, Hospitalidade e Lazer compreendem tecnologias relacionadas aos processos de recepção, viagens, eventos, gastronomia, serviços de alimentação e bebidas, entretenimento e interação. Abrangem planejamento, organização, operação e avaliação de produtos e serviços inerentes ao turismo, hospitalidade e lazer, integradas ao contexto das relações humanas em diferentes espaços geográficos e dimensões socioculturais, econômicas e ambientais.

A organização curricular dos cursos contempla conhecimentos relacionados a: leitura e produção de textos técnicos; raciocínio lógico; historicidade e cultura; línguas estrangeiras; ciência, tecnologia e inovação; tecnologias sociais, empreendedorismo, cooperativismo e associativismo; prospecção mercadológica e marketing; tecnologias de comunicação e informação; desenvolvimento interpessoal; legislação; normas técnicas; saúde e segurança no trabalho; gestão da qualidade; responsabilidade e sustentabilidade social e ambiental; qualidade de vida; ética profissional (Resolução CNE/ CEB n. 1, 2014).

Neste sentido, ofertar espaços de aprendizagem - que podem ser caracterizados como Laboratórios - que proporcionem o aprendizado teórico-prático para os discentes dos cursos técnicos do Eixo Turismo, Hospitalidade e Lazer cumprem as orientações constantes nas normativas do Ministério da Educação, como: a Lei de Diretrizes e Bases da Educação Nacional (Lei n. 9.394, 1996), as Diretrizes para a Educação Profissional e Técnica de Nível Médio (Resolução CNE/ CEB n. 6, 2012) e o Catálogo Nacional de Cursos Técnicos (Resolução CNE/CEB n. 1, 2014).

Além de cumprir tais orientações, são oportunidades de contribuir de forma aplicada para o exercício dos perfis profissionais propostos por cada curso do Eixo, auxiliando no pleno desenvolvimento de conhecimentos, de saberes e de competências profissionais e pessoais requeridas pela natureza do seu trabalho.

Assim, podem responder, de forma original e criativa, aos constantes desafios da vida cidadã e profissional dos discentes deste Eixo Tecnológico.

\section{O curso técnico em Eventos}

O curso técnico em Eventos ofertado pelo IFRS Campus Osório, desde 2018, prevê componentes curriculares organizados num corpo de conhecimentos que articula saberes básicos, técnicos e práticos, ofertados em três semestres letivos, com carga horária total de 957 horas (Resolução CONCAMPO n. 22, 2017 \& Resolução CONCAMPO n. 22, 2018).

Para o desenvolvimento das competências, habilidades e atitudes demandadas de tais profissionais foi estruturado o "Laboratório de Turismo e Hospitalidade" (previsto no projeto pedagógico do curso), como Projeto de Ensino vinculado ao Eixo Tecnológico Turismo, Hospitalidade e Lazer, no IFRS Campus Osório. Foi planejado como um espaço voltado para docentes e discentes dos cursos integrados ao referido eixo e tem como principal objetivo ser um núcleo de referência educacional em Turismo, Hospitalidade e Lazer.

O laboratório reúne três subáreas, a saber: Educação e Turismo, Turismo e Desenvolvimento Regional e Eventos. Nele se desenvolvem atividades práticas voltadas ao ensino, pesquisa e extensão na área de Turismo e Hospitalidade, nas formas de realização, organização e/ou apoio. Atua no contexto de desenvolvimento do turismo local e regional, de forma colaborativa com as demais áreas do conhecimento.

A geração atual possui contato constante com diferentes tecnologias necessitando, portanto, que os conteúdos abordados nos cursos sejam trabalhados de formas diversificadas. Sabe-se que as competências 
são melhores desenvolvidas em ambientes que permitam a exploração, de forma ativa e participativa, dos estudantes e que diferentes espaços ou ambientes de aprendizagem podem ser mais interessantes para ao aluno do que ambientes tradicionais de sala de aula e laboratórios de informática (Cortelazzo, et al, 2018).

Diante disso, objetiva-se proporcionar conhecimentos teórico-práticos para além das atividades regulares de ensino, proporcionando um aprendizado que corrobore na formação integral do aluno, sendo um facilitador para seu ingresso no mundo do trabalho, em distintos ambientes de aprendizagem.

\section{MetOdOLOGIA}

O desenvolvimento das competências mencionadas supõe a adoção de metodologias centradas no sujeito que aprende, ancorando-se no planejamento sistemático das atividades pedagógicas, em que não há dissociação entre teoria e prática para a educação profissional.

Cortelazzo et al. (2018) discorre sobre os diversos métodos de ensino, e, analisando-os, verifica-se que o espaço de aprendizagem denominado Laboratório de Turismo e Hospitalidade permite que se possa utilizar destes diferentes métodos, como apresentação de palestra, colóquios, debate, investigação, discussão, projeto, entre outros.

As Diretrizes para a Educação Profissional e Técnica de nível médio definem a orientação para os cursos Técnicos (Resolução CNE/CEB n. 6, 2012). Neste sentido, o currículo de quaisquer dos cursos da modalidade de Educação Profissional Tecnológica, em todas as suas formas de oferta e de organização deve ser construído a partir destes dois eixos norteadores essenciais: o trabalho como princípio educativo e a pesquisa como princípio pedagógico.

A instalação do Laboratório de Turismo e Hospitalidade foi realizada após o levantamento de alternativas que considerassem os recursos físicos e humanos da IE, bem como a participação em edital de Projetos de Ensino de 2018 que permitiu a implantação do referido Laboratório e a seleção de um bolsista remunerado, vinculado ao Curso Técnico em Eventos Subsequente ao Ensino Médio.

Em seu planejamento, o cronograma de implantação do Laboratório determinou para o primeiro semestre de 2018 a definição do local de instalação, o levantamento do mobiliário e demais recursos físicos e equipamentos necessários. Este período foi de organização do espaço e do planejamento das ações, contando com a presença de uma bolsista de ensino com carga horária de 8 horas semanais.

Para o segundo semestre foram previstas ações para cada subárea prevista para as ações do Laboratório: Educação e Turismo; Turismo e Desenvolvimento Regional e Eventos. Os primeiros resultados das atividades desenvolvidas pelo Laboratório despontaram ao longo de sua execução.

\section{Resultados e Discussõ̃es}

Os primeiros resultados da implantação do Laboratório de Turismo e Hospitalidade no IFRS - Campus Osório já foram vislumbrados. Algumas atividades para atendimento às demandas da comunidade externa e interna foram planejadas e executadas, conforme relatado a seguir.

A oferta do curso de "Atendimento ao Turista" buscou atender uma demanda do poder público municipal (Secretaria Municipal de Turismo). O curso teve como objetivo contribuir para a qualificação dos colaboradores das secretarias municipais que atuam diretamente com $\mathrm{o}$ atendimento ao turista no município de Osório. São pessoas que operam na "linha de frente" do turismo, prestando assistência de diversas formas nas centrais de atendimento ao turista.

A programação do curso contemplou noções básicas de Turismo; aspectos sobre a atratividade turística local e regional; a Hospitalidade e o bem receber; o profissional do atendimento e a comunicação em busca de um serviço de excelência. Finalizando o curso, foi realizada a atividade prática de um city tour, objetivando reconhecer as atratividades locais e os principais serviços turísticos ofertados no município, totalizando 20 horas de atividades teórico-práticas.

A oferta do curso "Recepção e Credenciamento em Eventos" se deu para atender a uma demanda interna dos acadêmicos do curso técnico subsequente em Eventos. O objetivo do curso foi qualificar os alunos para que pudessem ofertar o serviço de recepção a eventos, principalmente os realizados no Campus Osório.

Na formação, os alunos tiveram o acesso a conteúdos sobre o profissional de recepção de eventos, a sua contratação, o atendimento a diversos públicos, a postura profissional e pessoal, a comunicação em busca de um serviço de excelência e o reconhecimento da atividade do profissional da recepção em eventos por setor de atuação, totalizando 16 horas/aula. 
Foi iniciado um projeto de pesquisa submetido ao edital de fluxo contínuo do IFRS, denominado "Análise do mercado de eventos no Litoral Norte Gaúcho: o mapeamento dos espaços e das empresas organizadoras de eventos", desenvolvido por docentes do Eixo de Turismo, Hospitalidade e Lazer, com acadêmicos do Curso Técnico em Eventos, contando com bolsista remunerado e bolsista voluntário.

O objetivo do projeto foi analisar o mercado de eventos no Litoral Norte Gaúcho, através do mapeamento dos espaços e das empresas organizadoras de eventos, em cinco municípios: Santo Antônio da Patrulha, Osório, Capão da Canoa, Tramandaí e Torres. O referido projeto terá continuidade em 2019 e contará com a participação de um bolsista matriculado em um curso técnico de nível médio.

Tais práticas são oportunidades de contribuir para o desenvolvimento de conhecimentos, de saberes e de competências profissionais e pessoais requeridas pela natureza do trabalho em Turismo, Hospitalidade e Lazer. Também possibilitam condições para responder, de forma original e criativa, aos constantes desafios da vida cidadã e profissional do público atendido.

Com tais resultados, em 2019, o projeto "Laboratório de Turismo e Hospitalidade" foi submetido novamente a um edital de apoio a projetos como Projeto de Ensino, e, mais uma vez, foi contemplado com uma bolsa de ensino para um aluno técnico de nível médio, destinada a um acadêmico do curso técnico em Eventos do Campus Osório.

\section{AplicabILIDADE}

Sabe-se que a utilização de espaços de aprendizagem não é algo inovador no meio acadêmico, mas, mesmo assim, sua instalação e operacionalização são ações desafiadoras para as Instituições de Ensino.

A provocação para as Instituições de Ensino está em realmente transformar seus espaços de aprendizagens tradicionais em espaços dinâmicos e interativos, em atendimento as novas características comportamentais das atuais gerações.

Acredita-se que os resultados obtidos a partir da criação de um ambiente de aprendizagem para a comunidade acadêmica de cursos técnicos de nível médio - no caso o curso de Eventos, possa, ainda, incentivar a criação de outras propostas de espaços e o fomento às discussões das práticas pedagógicas utilizadas pelos docentes, que permitam o desenvolvendo de saberes e competências profissionais indispensáveis ao exercício profissional e também da formação do cidadão.

Ainda, ao atender as demandas locais e regionais relacionadas ao Turismo, a proposta pode contribuir de alguma forma com o desenvolvimento turístico, atendendo também a necessidade de formação integral do aluno e de contribuição da IEs à comunidade que está inserida.

\section{Considerações finais}

O objetivo do Laboratório, enquanto espaço de aprendizagem, é ser um núcleo de referência educacional em Turismo, Hospitalidade e Lazer no seu âmbito de atuação. Também busca criar oportunidades para $\mathrm{o}$ atendimento aos perfis profissionais propostos para cada curso do Eixo de Turismo Hospitalidade e Lazer, em especial ao curso Técnico em Eventos, em andamento na Instituição.

A indissociabilidade entre educação e prática social, teoria e prática, no processo de ensino-aprendizagem, garante a interdisciplinaridade no currículo e na prática pedagógica. Visa à superação da fragmentação de conhecimentos e de segmentação da organização curricular, aprimorando as competências necessárias para atuação profissional. Isto é o que se propõe a instalação do Laboratório de Turismo e Hospitalidade no IFRS - Campus Osório.

Há muitos desafios no âmbito da educação e da formação em Turismo, Hospitalidade e Lazer para serem superados. Acredita-se que as instituições de ensino possam suplantar as adversidades e corroborar para o desenvolvimento turístico local e regional, para que tenha uma oferta de serviços qualificados por meio da integração da academia com a comunidade externa, observando e procurando atender as demandas locais e regionais.

Alguns fatores limitadores ainda precisam ser superados na instalação do Laboratório de Turismo e Hospitalidade, principalmente em termos de estrutura física, como ampliação do espaço e aquisição dos demais equipamentos para o desenvolvimento de atividades práticas de ensino e de extensão.

Além disso, a prática pedagógica do corpo docente deve ser constantemente repensada em virtude das novas características comportamentais das novas gerações e das demandas do mundo do trabalho. 
É preciso que se amplie a participação de docentes de áreas correlatas, contribuindo na formação integral do aluno para o mundo do trabalho.

Como fatores facilitadores, os resultados obtidos demonstram que o caminho vislumbrado está alinhado com o compromisso da Educação Profissional, articulando ensino, pesquisa e extensão em Turismo, Hospitalidade e Lazer, extrapolando a questão de ser um projeto vinculado apenas ao ensino.

De acordo com Severino (2016) não deve haver distinção entre ensino, pesquisa e extensão, pois não são concebidos como processos isolados de transmissão da ciência e a socialização de seus produtos não deve ser desvinculada de seu processo de geração.

Finalmente, há que se fazer sempre uma revisão do papel da educação, dos espaços e das práticas docentes no campo do Turismo, da Hospitalidade e do Lazer. Deve-se sempre considerar a necessidade de avanços no processo educativo, considerando a articulação com o mundo do trabalho, para que as competências, "saber", o "saber fazer", o "saber ser" e o "saber conviver" sejam motivadas nos espaços de aprendizagens.

\section{Referências}

Brasil. V.L.B. (2016). Competências para o Administrador. Um enfoque para o saber ser e o saber fazer. São Paulo: Laos.

Buratto, M., Tomelin, C. A., Hostins, R. C. L. (2013). Reflexões sobre a interdisciplinaridade no ensino do turismo. In: Ruschmann, D., Tomelin, C.A. (orgs): Turismo, ensino e práticas interdisciplinares. (pp. 145-160). Barueri, SP: Manole.

Ciavatta, M., Ramos, M. (2012). A Era das Diretrizes: A disputa pelo projeto de educação dos mais pobres. Revista Brasileira de Educação. 17, (49), 11-39. Recuperado de: http:// www.scielo.br/pdf/rbedu/v17n49/a01v17n49.pdf.

Cortelazzo, A. L. et al. (2018). Metodologias ativas e personalizadas de aprendizagem para refinar seu cardápio metodológico. Rio de Janeiro: Alta Books.

Fleury, A., Fleury, M.T.L. (2001). Construindo o conceito de competência. Revista de Administração Contemporânea RAC. (Edição Especial 5, 183-196). Recuperado de: http:// www.scielo.br/scielo.php?script=sci_arttext\&pid=S141565552001000500010 .

Gesser, V. Currículo e novas tecnologias no ensino superior: avanços, desdobramentos, implicações e limites. In: Ruschmann, D., Tomelin, C.A. (orgs): Turismo, ensino e práticas interdisciplinares. (pp. 161-172). Barueri, SP: Manole.
Lei n. 9.394, de 20 de dezembro de 1996. Estabelece as diretrizes e bases da educação nacional. Recuperado de: http:// www.planalto.gov.br/ccivil_03/leis/L9394.htm.

Parecer CNE/CEB n. 11, de 12 de junho de 2008. Proposta de instituição do Catálogo Nacional de Cursos Técnicos de Nível Médio. Recuperado de: http://portal.mec.gov.br/setec/ arquivos/pdf/pceb011_08.pdf.

Perrenout, P. (1999). Construir as competências desde a escola. Porto Alegre: Artes Médicas Sul.

Resolução CEB n. 4, de 8 de dezembro de 1999. Institui as Diretrizes Curriculares Nacionais para a Educação Profissional de Nível Técnico. Recuperado de: http:// portal.mec.gov.br/dmdocuments/rceb004_99.pdf.

Resolução CONCAMPO n. 22, de 28 de agosto de 2017. Aprova o Projeto Pedagógico do Curso Técnico em Eventos Subsequente ao Ensino Médio. Recuperado de: https:// osorio.ifrs.edu.br/site/midias/ arquivos/201791710547446resolucao_22-2017_ (retificacao).pdf.

Resolução CONCAMPO n. 22, de 3 de setembro de 2018. Aprova a alteração do Projeto Pedagógico do Curso Técnico em Eventos Subsequente ao Ensino Médio. Recuperado de: https://osorio.ifrs.edu.br/site/midias/ arquivos/2018817114338678resolucao_22-2018.pdf.

Resolução CNE/CEB n. 6, de 30 de setembro de 2012. Define Diretrizes Curriculares Nacionais para a Educação Profissional Técnica de Nível Médio. Recuperado de: http:// portal.mec.gov.br/index.php? option=com_docman\&view=download\&alias $=11663$ rceb006-12-pdf\&category_slug=setembro-2012pdf\&Itemid=30192.

Resolução CNE/CEB n. 1, de 5 de dezembro de 2014. Atualiza e define novos critérios para a composição do Catálogo Nacional de Cursos Técnicos, disciplinando e orientando os sistemas de ensino e as instituições públicas e privadas de Educação Profissional e Tecnológica quanto à oferta de cursos técnicos de nível médio em caráter experimental, observando o disposto no art. 81 da Lei n.o 9.394/96 (LDB) e nos termos do art. 19 da Resolução CNE/CEB n.ㅇ 6/2012. Recuperado de: http://portal.mec.gov.br/ index.php? option=com docman\&view=download\&alias=16705-res1 -2014-cne-ceb-05122014\&category slug=dezembro-2014 -pdf\&Itemid=30192.

Severino, A.J. (2016). Metodologia do trabalho científico. (24a ed.). São Paulo: Cortez.

Souza, P.N.P., Silva, E.B. (1997). Como entender e como aplicar a nova LDB. Lei n.o 9394/1996. São Paulo: Pioneira.

Sulzer, E. (2004). Objetivar as competências de interação: crítica social do saber-ser. In: Tomasi, A. (org). Da qualificação à competência: pensando o século XXI. (pp. 93-105). Campinas: Papirus. 
Trigo, L. G. G. (2008). Apresentação à edição brasileira. In: Airey, D.; Tribe, J. (org). Educação internacional em turismo. (C. Szlak Trad.). (pp.11-13). São Paulo: editora SENAC São Paulo.

\section{CONTRIBUIÇÃO dOS AUTORES}

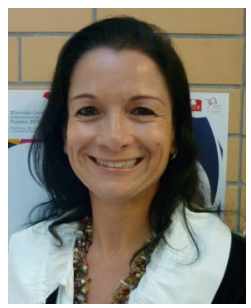

Ana Lúcia Olegário Saraiva Elaboração do projeto. Participou do planejamento, execução e confecção do artigo: fundamentação teórica, análise dos resultados, discussões aplicabilidade e revisão do artigo.

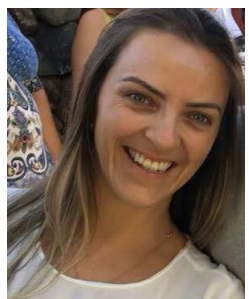

Bianca Pugen - Elaboração do projeto. Participou do planejamento, execução e confecção do artigo, em especial na análise dos resultados, discussões e aplicabilidade e revisão do artigo.

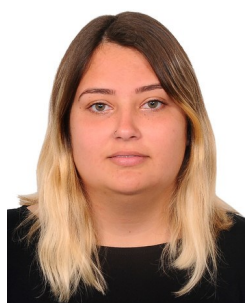

Vanessa de Souza Chaves - Como bolsista, acompanhou as atividades realizadas e apoiadas pelo Laboratório, contribuindo na análise dos resultados, discussões e aplicabilidade. 